Revista Brasileira de Agricultura Irrigada v.13, nº.6, p. 3757 - 3764, 2019

ISSN 1982-7679 (On-line)

Fortaleza, CE, INOVAGRI - http://www.inovagri.org.br

DOI: $10.7127 /$ rbai.v13n6001160

Protocolo 1160.19 - 04/05/2020 Aprovado em 11/05/2020

\title{
ÁGUA SALINA E FORMAS DE ADUBAÇÃO NA CULTURA DA ABOBRINHA
}

\author{
Francisco Hermeson Rodrigues Costa ${ }^{1}$, José Marcelo da Silva Guilherme ${ }^{1}$, Andreza da Silva \\ Barbosa $^{1}$, Juvenaldo Florentino Canjá ${ }^{2}$, Márcio Henrique da Costa Freire ${ }^{3}$, Geocleber Gomes de \\ Sousa $^{4}$
}

\section{RESUMO}

O objetivo deste trabalho foi avaliar a influência da irrigação com água salina sob diferentes formas de adubação nas trocas gasosas da cultura da abobrinha. O experimento foi realizado na área experimental da Unidade de Produção de Mudas Auroras (UPMA), na Universidade da Integração Internacional da Lusofonia Afro-Brasileira (UNILAB), Redenção, Ceará. O delineamento experimental utilizado foi inteiramente casualizado, em arranjo fatorial $2 \times 3$, com 4 repetições. $\mathrm{O}$ fator 1 corresponde a dois níveis de condutividade elétrica (A1 - água de abastecimento $0,8 \mathrm{dS} \mathrm{m}^{-1} \mathrm{e}$ A2 - solução salina de $2,5 \mathrm{dS} \mathrm{m}^{-1}$ ); e o fator 2 corresponde a três formas de adubação: T1= adubação com cinza vegetal $(100 \%)$; T2= adubação mineral com NPK (100\% da dose recomendada); T3= controle (sem adubação). Aos 26 dias após o transplantio (DAT), foram analisadas as seguintes variáveis: fotossíntese $(A)$, transpiração $(\mathrm{E})$, condutância estomática (gs) e o índice clorofila (SPAD). A abobrinha irrigada com água de $\left(0,8 \mathrm{dS} \mathrm{m}^{-1}\right)$ alinhado à adubação com Cinza vegetal, mostrou-se superior as demais adubações, para as variáveis fotossíntese, transpiração e a condutância estomática. A forma de adubação com NPK foi a mais eficiente para o índice de clorofila irrigado com água de baixa salinidade.

Palavras-chave: Cucurbita pepo L., salinidade, fotossíntese.

\section{SALINE WATER AND FORMS OF FERTILIZATION IN THE ZUCCHINES CULTURE}

\footnotetext{
ABSTRACT

The objective of this work was to evaluate the influence of saline water irrigation under different forms of fertilizer in the gas exchange of the zucchini culture. The experiment was conducted in the experimental area of the unit for the production of aurora seedlings (UPMA), at the University of the International Integration of Afro-Brazilian Lusophone (UNILAB), Redenção, Ceará. The

${ }^{1}$ Graduandos em Agronomia; Instituto de Desenvolvimento Rural; UNILAB; e-mail: hermesonrc@gmail.com; e-mail: marcelo03silva2013@gmail.com; e-mail: andrezabarbosaunilab@gmail.com;

${ }^{2}$ Mestrando em Engenharia Agrícola; UFC; e-mail: batchijuve@gmail.com;

${ }^{3}$ Mestrando em Ciência do Solo; UFC; e-mail: marciohcfreire@gmail.com;

${ }^{4}$ Doutor em Engenharia Agrícola; Professor da UNILAB; e-mail: sousagg@unilab.edu.br.
} 
experimental design used was entirely casualized, in a 2 × 3 factor arrangement, with 4 repetitions. Factor 1 corresponds to two levels of electrical conductivity (A1 - water supply $0.8 \mathrm{ds} \mathrm{m}^{-1}$ and A2 saline solution of $2.5 \mathrm{ds} \mathrm{m}^{-1}$ ); and factor 2 corresponds to three forms of fertilization: $\mathrm{T} 1=$ fertilization with vegetable ash $(100 \%)$; T2 = mineral adduction with NPK $(100 \%$ of recommended dose); T3= control (without fertilization). At 26 days after transplantation (DAT), the following variables were analyzed: photosynthesis $(\mathrm{A})$, transpiration $(\mathrm{E})$, stomatal conductance (gs) and the chlorophyll index (SPAD). The zucchini irrigated with water of $\left(0.8 \mathrm{dS} \mathrm{m}^{-1}\right)$ aligned to the fertilization with Vegetable ash, proved to be superior to the other fertilizations, for the variables photosynthesis, transpiration and stomatal conductance. The form of fertilization with NPK was the most efficient for the chlorophyll index irrigated with low salinity water.

Keywords: Cucurbita pepo L., salinity, photosynthesis.

\section{INTRODUÇÃO}

A cultura de abobrinha (Cucurbita pepo L.) é uma planta da família Cucurbitaceae, que tem como origem o continente americano (região central do México e sul dos Estados Unidos) (CARPES, 2008), entre as olerícolas, a abobrinha tem-se destacado pelo grande potencial para comercialização, pois possui boa aceitação para o mercado consumidor, além de representar opção produtiva o ano todo para os produtores (AZAMBUJA et al., 2015).

A salinidade, em muitas regiões de áreas áridas e semiáridas, constitui sério obstáculo ao sistema de produção. Ou seja, o excesso de sais no solo reduz a disponibilidade de água para as plantas, devido à redução do potencial osmótico na solução do solo, afetando o crescimento e produção das culturas (SOUSA et al., 2018; RODRIGUES et al., 2020).

A interação entre salinidade e nutrição mineral ainda é bastante dinâmica em plantas cultivadas em ambientes salinos. No entanto, a maioria das glicófitas ocorre sempre um desequilíbrio nutricional, principalmente, da redução na absorção de nutrientes essenciais à planta, devido à competição na absorção e transporte (SOUSA et al., 2010; OLIVEIRA et al., 2011). A forma de adubação orgânica ou mineral em meio salino revelam resultados promissores quanto a mitigação do estresse salino nas trocas gasosas de algumas culturas, como concluíram Sousa et al. (2018) utilizando o biofertilizante bovino na cultua da soja, Souza et al. (2019) com biofertilizante caprino na cultua da fava e Prazeres et al.
(2015) adubando com potássio a cultura do feijão.

O objetivo deste trabalho foi avaliar a influência da irrigação com água salina sob diferentes formas de adubação nas trocas gasosas da cultura da abobrinha.

\section{MATERIAL E MÉTODOS}

O experimento foi realizado na área experimental da Unidade de Produção de Mudas Auroras (UPMA), na Universidade da Integração Internacional da Lusofonia AfroBrasileira (UNILAB), Redenção, Ceará. Segundo a classificação de Köppen o clima da região é do tipo Aw', clima tropical com estação seca.

O delineamento experimental utilizado foi inteiramente casualizado, em arranjo fatorial $2 \times 3$, com 4 repetições. $O$ fator 1 corresponde a dois níveis de condutividade elétrica (A1 - água de abastecimento $0,8 \mathrm{dS} \mathrm{m}^{-}$ ${ }^{1}$ e A2 - solução salina de $2,5 \mathrm{dS} \mathrm{m}^{-1}$ ); e o fator 2 corresponde a três formas de adubação: $\mathrm{T} 1=$ adubação com cinza vegetal $(100 \%)$; T2= adubação mineral com NPK (100\% da dose recomendada); T3= controle (sem adubação).

Para a produção das mudas de abobrinha (Curcubita pepo L.), híbrido Corona F1 da Topseed Premium, as sementes foram semeadas em bandejas de polietileno, contendo 128 células, sendo utilizadas 2 bandejas e semeadas 200 células com uma semente cada.

Os vasos utilizados foram de material plástico flexível, com capacidade volumétrica 
de 11 litros (L), contendo substrato na proporção 3:1:1 de arisco, areia e matéria orgânica, respectivamente (Tabela 1), no qual uma amostra foi encaminhado para o laboratório de Solos da UFC, onde foram determinados os atributos químicos seguindo a metodologia (TEIXEIRA et al., 2017).

Tabela 1. Atributos químicos do substrato utilizado antes da aplicação da água salina.

\begin{tabular}{|c|c|c|c|c|c|c|c|c|c|}
\hline M.O. & $\mathrm{N}$ & $\mathrm{P}$ & $\mathrm{Mg}$ & $\mathrm{K}$ & $\mathrm{Ca}$ & $\mathrm{Na}$ & \multirow{2}{*}{$\mathrm{pH}$} & \multirow{2}{*}{$\operatorname{PST}(\%)$} & \multirow{2}{*}{$\mathrm{CE}$} \\
\hline $\mathrm{g} \mathrm{kg}^{-1}$ & & $\mathrm{mg} \mathrm{kg}^{-1}$ & \multicolumn{4}{|c|}{$\mathrm{cmol}_{\mathrm{c}} \mathrm{dm}^{-3}$} & & & \\
\hline 4,34 & 0,26 & 65 & 1,2 & 0,65 & 1,2 & 0,33 & 6,2 & 7 & 1,19 \\
\hline
\end{tabular}

M.O= Matéria orgânica; $\mathrm{PST}=$ porcentagem de sódio trocável; $\mathrm{CE}=$ condutividade elétrica.

Para cada vaso foi transplantado uma muda aos 12 dias após a semeadura (DAS). Aos 10 dias após o transplantio (DAT) iniciou-se a irrigação com água salina.

A quantidade dos sais $\mathrm{NaCl}$, $\mathrm{CaCl}_{2} \cdot 2 \mathrm{H}_{2} \mathrm{O}$ e $\mathrm{MgCl}_{2} \cdot 6 \mathrm{H}_{2} \mathrm{O}$, utilizadas no preparo das águas de irrigação são determinadas de forma a se obter a condutividade elétrica da água (CEa) desejada na proporção 7:2:1, conforme Rhoades et al. (2000). A irrigação com as águas salinas foi iniciada após o desbaste com uma frequência de irrigação diária de acordo com o princípio do lisímetro de drenagem (PUÉRTOLAS et al., 2017), fornecendo-se o volume de água evapotranspirada a cada $24 \mathrm{~h}$, para manutenção do substrato com umidade correspondente a $90 \%$ da capacidade de campo. A adubação mineral utilizada foi a recomendação dada por Filgueira (2012), a qual compreende $140 \mathrm{~kg} \mathrm{ha}^{-1}$ de $\mathrm{N}, 300 \mathrm{~kg} \mathrm{ha}^{-1}$ de $\mathrm{P}_{2} \mathrm{O}_{5}$ e $150 \mathrm{~kg} \mathrm{ha}^{-1}$ de $\mathrm{K}_{2} \mathrm{O}$. No entanto, foi quantificada até a fase experimental. Para a cinza vegetal, foi determinada calculando a quantidade de nutrientes presentes no substrato, levando em consideração a densidade e o volume de substrato colocado em cada vaso e multiplicando-se em seguida o valor encontrado pelas quantidades de $\mathrm{N}, \mathrm{P}$ e $\mathrm{K}$ presentes na análise.

A cinza vegetal utilizada foi proveniente da queima de um cultivo de cana-de-açúcar. Os teores de elementos minerais (Tabela 2), na composição química da cinza vegetal, foram analisados conforme metodologia sugerida por Malavolta et al. (1997).

Tabela 2. Composição de macro e micronutrientes presentes na cinza vegetal

\begin{tabular}{|c|c|c|c|c|c|c|c|c|c|}
\hline $\begin{array}{c}\text { Adubo } \\
\text { orgânico }\end{array}$ & $(\mathrm{N}$ & $\mathrm{P}$ & $\mathrm{K}$ & $\mathrm{Ca}$ & $\mathrm{Mg})$ & $(\mathrm{Fe}$ & $\mathrm{Cu}$ & $\mathrm{Zn}$ & $\mathrm{Mn})$ \\
\hline \multirow{2}{*}{$\begin{array}{l}\text { Cinza } \\
\text { vegetal }\end{array}$} & \multicolumn{5}{|c|}{----------------- $\left(\mathrm{g} \mathrm{L}^{-1}\right)$------------- } & \multicolumn{4}{|c|}{ - $\left(\mathrm{mg} \mathrm{L}^{-1}\right)$----- } \\
\hline & 0,4 & 1,13 & 54,4 & 28,7 & 13,9 & 7819,1 & 10,5 & 37,8 & 240,8 \\
\hline
\end{tabular}

Aos 26 DAT, foram mensurados os seguintes parâmetros fisiológicos: fotossíntese (A), transpiração (E) e a condutância estomática (gs), através de um analisador de gás no infravermelho IRGA (LI 6400 XT da LICOR), em sistema aberto, com fluxo de ar de $300 \mathrm{~mL} \mathrm{min-}^{1}$; as medições foram feitas entre 8 e $11 \mathrm{~h}$, em folhas completamente expandidas. Os níveis relativos de clorofilas foram mensurados usando método não destrutivo com um medidor portátil de clorofila (SPAD - 502 Plus). As medidas foram feitas nas mesmas folhas usadas para medir as trocas gasosas.

Os dados após coletados foram submetidos à análise de variância (ANOVA) e a testes de médias pelo teste de Tukey ao nível de 5\% (*) de probabilidade, utilizando-se o programa computacional ASSISTAT. 7.6 Beta (SILVA \& AZEVEDO, 2016). 


\section{RESULTADOS E DISCUSSÃO}

Observa-se na Tabela 1 que houve interação entre os fatores $\mathrm{A} \times \mathrm{T}$, condutividade elétrica (A), e formas de adubação (T), respectivamente, fotossíntese condutância clorofila (SPAD index) aos 26 dias após o transplantio (DAT).

Tabela 1. Resumo da análise de variância (ANOVA) para a condutância estomática (gs), fotossíntese $(A)$, transpiração $(\mathrm{E})$ e índice SPAD da cultura da abobrinha sob a influência da irrigação com água salina e diferentes formas de adubação nas suas trocas gasosas.

\begin{tabular}{cccccc}
\hline \multirow{2}{*}{ FV } & \multirow{2}{*}{ GL } & \multicolumn{4}{c}{ Quadrado médio } \\
\cline { 3 - 6 } & & $A$ & $\mathrm{E}$ & $\mathrm{gs}$ & $\mathrm{SPAD}$ \\
\hline Condutividade elétrica (A) & 1 & $46,39820 * *$ & $2,63344 * *$ & $0,40560 * *$ & $517,45 * *$ \\
Formas de adubação (T) & 2 & $27,42207 * *$ & $1,74865 * *$ & $0,26289 * *$ & $514,23 * *$ \\
A x T & 2 & $19,90712^{*}$ & $2,63679 * *$ & $0,51886 * *$ & $40,72 * *$ \\
Tratamentos & 5 & $28,21131^{* *}$ & $2,28086 * *$ & $0,39382 * *$ & $299,29 * *$ \\
Resíduo & 18 & 3,54863 & 0,23764 & 0,025 & 2,84 \\
CV (\%) & - & 20,94 & 16,78 & 37,87 & 5,06 \\
\hline
\end{tabular}

FV: Fonte de variação; GL: Grau de liberdade; CV(\%): Coeficiente de variação; (**) significativo ao nível de 1\% de probabilidade $(\mathrm{p}<.01)$; $(*)$ significativo ao nível de $5 \%$ de probabilidade $(.01=<\mathrm{p}<.05)$; (ns) não significativo $(\mathrm{p}>=$ $.05)$.

A análise da interação entre a condutividade elétrica da água de irrigação e formas de adubação para fotossíntese (Figura 1), verificou-se que o maior valor para taxa

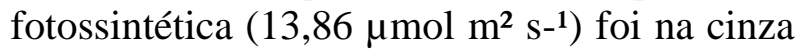
vegetal (T1) quando irrigada com água de baixa salinidade. $O$ incremento da taxa fotossintética nesta adubação pode estar relacionado, possivelmente, devido a cinza possuir elevada quantidade de potássio, visto que este nutriente contribui com fundamentais eventos fotoquímicos na planta, como: ativação enzimática, síntese de proteínas, extensão celular, osmorregulação, abertura e fechamento dos estômatos (ROMHELD; KIRKBY, 2010).

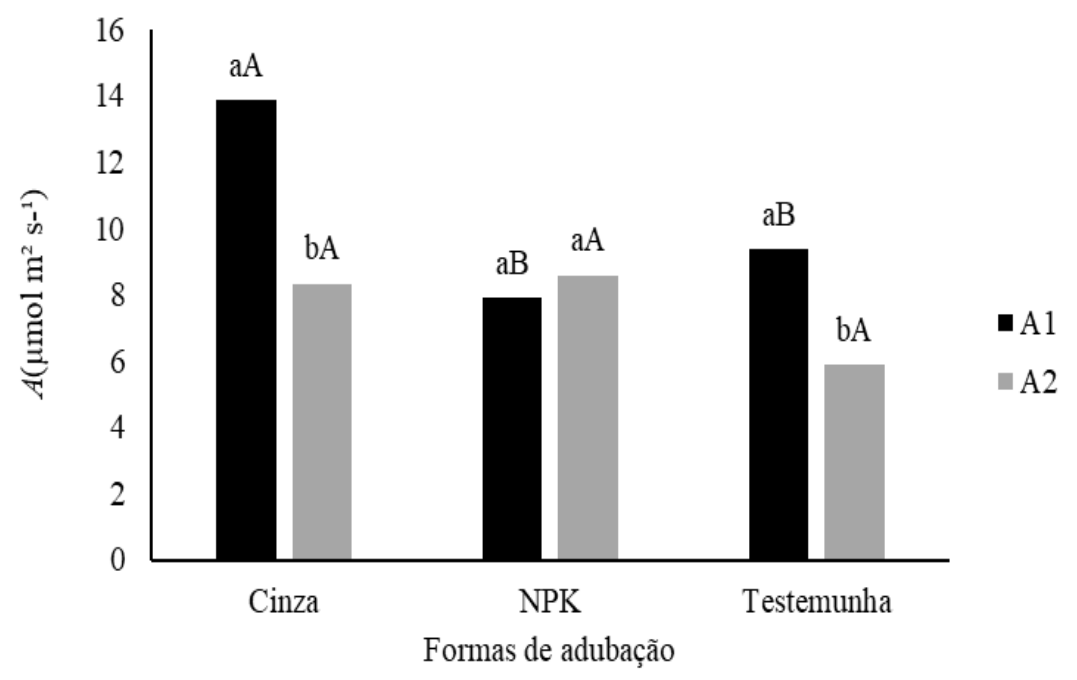

Figura 1. Fotossíntese na cultura da abobrinha com irrigação com água salina sobre diferentes formas de adubação. As médias seguidas pela mesma letra não diferem estatisticamente entre si: minúsculas e maiúsculas nas colunas sob o teste de Tukey $(\mathrm{p}<0,005)$. 
Tendência similar foi verificado por Souza et al. (2019) avaliando a fotossíntese em plantas de fava irrigada com água de alta salinidade em solo com biofertilizante caprino, e por Sousa et al. (2018) em plantas de soja em solo com biofertilizante bovino. O teste de comparação de média (figura 2) demonstrou que a interação entre os níveis de condutividade elétrica e as diferentes formas de adubação, que a fertilização com NPK (100 $\%$ da dose recomendada) promoveu maior transpiração da cultura na água de $2,5 \mathrm{dS} \mathrm{m}^{-1}$ (2,65 mmol $\left.\mathrm{m}^{2} \mathrm{~g}^{-1}\right)$ apesar de não diferir estatisticamente das demais estratégias.

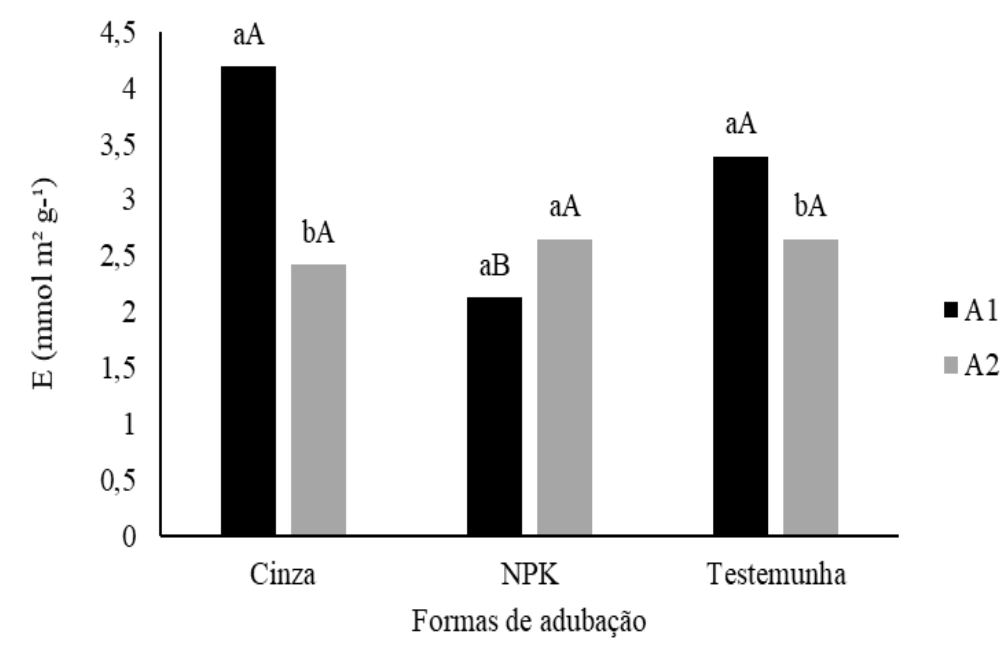

Figura 2. Transpiração na cultura da abobrinha com irrigação com água salina sobre diferentes formas de adubação. As médias seguidas pela mesma letra não diferem estatisticamente entre si: minúsculas e maiúsculas nas colunas sob o teste de Tukey $(\mathrm{p}<0,005)$.

O fornecimento adequado do íon potássio, além de promover maior abertura estomática, induz uma maior transpiração, que é um componente essencial para o ajustamento osmótico em plantas sobre estresse salino por se concentrar principalmente no citosol (SILVEIRA et al., 2016). Já Sousa et al. (2020) utilizando biofertilizante bovino na cultura do quiabo em solo irrigado com água salina, obtiveram redução da transpiração, porém com menor proporção coma presença do insumo orgânico. Na Figura 3, o efeito da condutividade elétrica da água de irrigação para condutância estomática (gs) não apresentou diferença significativa na água de menor quantidade de sais $\left(0,8 \mathrm{dS} \mathrm{m}^{-1}\right)$, verificando que o tratamento (T1) com cinza vegetal $(100 \%)$, foi superior $\left(1,01 \mathrm{~mol} \mathrm{~m}^{2} \mathrm{~s}^{-1}\right)$ em comparação ao tratamento (T2) adubação mineral (100\%), e (T3) controle, entretanto houve uma diferença significativa para a água salina $\mathrm{A} 2$ de $2,5 \mathrm{dS} \mathrm{m}^{-1}$. Observa-se que no uso de água salina (A2) na irrigação, combinado com a adubação com NPK tem-se resultados superior $\left(0,37 \mathrm{~mol} \mathrm{~m}^{2} \mathrm{~s}^{-1}\right)$ às demais formas de adubações. 


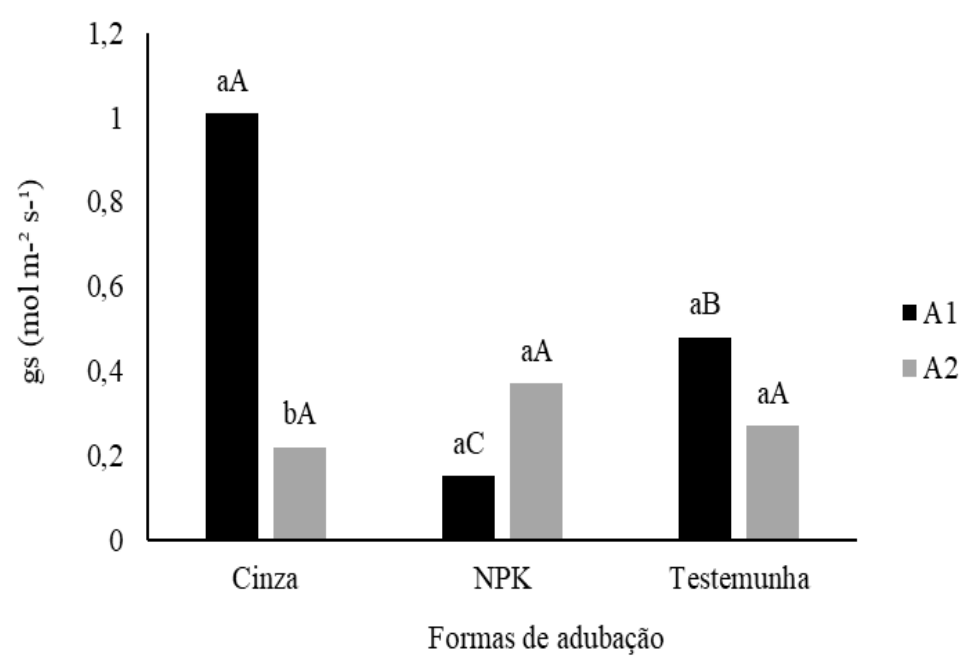

Figura 3. Condutância estomática (A), fotossíntese (B) e transpiração (C) na cultura da abobrinha com irrigação com água salina, sobre diferentes formas de adubação. As médias seguidas pela mesma letra não diferem estatisticamente entre si: minúsculas e maiúsculas nas colunas sob o teste de Tukey $(\mathrm{p}<0,005)$.

De acordo com este resultado presumese que esta adubação foi suficiente para impulsionar a abertura estomática sobre efeito estressante. Resultados similares foram observados por Prazeres et. al. (2015) avaliando cloreto de potássio na cultura do feijão-cuapi irrigada com água salina. De forma similar, Sousa et. al. (2020) também constataram redução da condutância estomática sob estresse salino, porém com menor intensidade quando utilizaram biofertilizante bovino como forma orgânica na cultura do quiabo.

De acordo com a figura 4 , que a água de baixa salinidade evidencio maior índice SPAD em todas formas de adubação, no entanto, a mineral com NPK foi superior. Possivelmente o nitrogênio impulsionou esse resultado, ou seja, aumentou o teor relativo de clorofila a partir da quantidade de luz absorvida pela folha e consequentemente o índice SPAD.

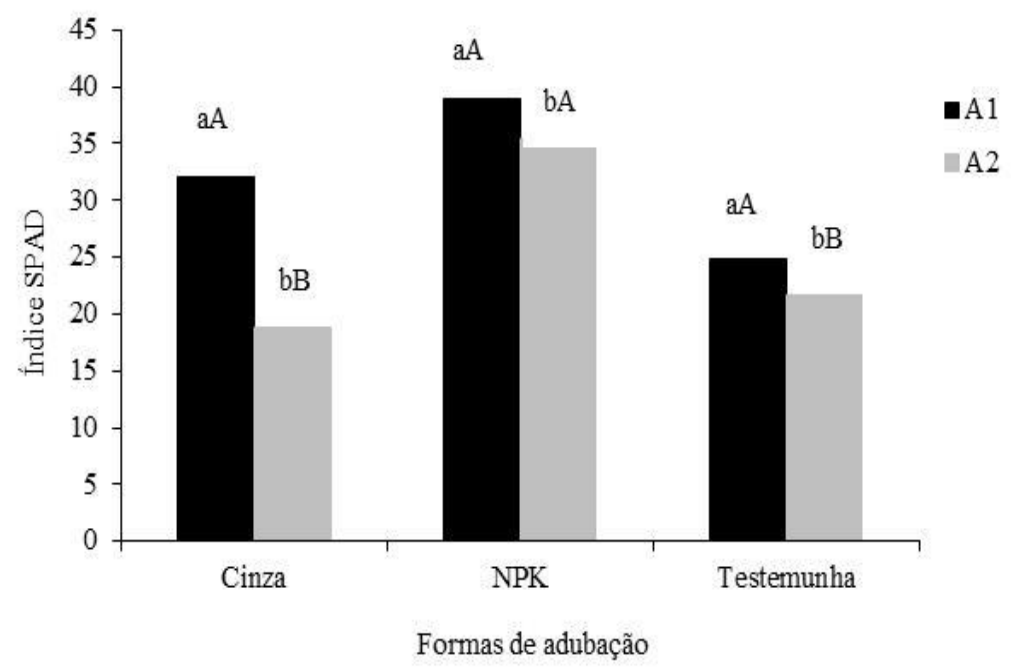

Figura 4. Índice SPAD na cultura da abobrinha com irrigação com água salina, sobre diferentes formas de adubação. As médias seguidas pela mesma letra não diferem estatisticamente entre si: minúsculas e maiúsculas nas colunas sob o teste de Tukey $(\mathrm{p}<0,005)$.

$O$ efeito negativo da água de alta salinidade para os teores de clorofila em plantas de abobrinha em todas as formas de adubação corroboram com Munns e Tester
(2008), onde esses autores descrevem que essa redução são resultados dos desequilíbrios nas atividades fisiológicas e bioquímicas promovidas pelo teor de sais, estimulando a 
atividade enzimática da clorofilase que degrada as moléculas do pigmento fotossintetizante e induz a destruição estrutural dos cloroplastos, provocando também o desbalanceamento e perda de atividade das proteínas de pigmentação.

Corroborando com os dados deste estudo, Dias et al. (2019) também verificaram que a adubação mineral com potássio não atenua os efeitos negativos da salinidade água na clorofila de folhas da cultura da acerola. Já Freire et al. (2013) aplicando biofertilizante como adubo orgânico em solo cultivado com a cultura do maracujazeiro amarelo irrigada com água salina também detectaram redução do teor de clorofila.

\section{CONCLUSÕES}

A abobrinha irrigada com água de $0,8 \mathrm{dS}$ $\mathrm{m}^{-1}$ alinhado à adubação com Cinza vegetal, mostrou-se superior as demais adubações, para as variáveis fotossíntese, transpiração e a condutância estomática.

A forma de adubação com NPK foi mais eficiente para o índice de clorofila irrigado com água de baixa salinidade.

\section{REFERÊNCIAS BIBLIOGRÁFICAS}

AZAMBUJA, L.O.; BENETT, C.G.S.; BENETT, K.S.S.; COSTA, E. Produtividade da abobrinha 'Caserta' em função do nitrogênio e gel hidrorretentor. Científica, Jaboticabal-SP, v. 43, n. 4, p. 353-358, 2015.

CARPES, R.H.; LÚCIO, A.D.; STORCK, L.; LOPES, S.J.; ZANARDO, B.; PALUDO, A.L. Ausência de frutos colhidos e suas interferências na variabilidade da fitomassa de frutos de abobrinha italiana cultivada em diferentes sistemas de irrigação. Revista Ceres, v.55, p.590-595, 2008.

DIAS, A. S., LIMA, G. S., PINHEIRO, F. W. A., GHEYI, H. R., SOARES, L. A. dos A. Gas exchanges, quantum yield and photosynthetic pigments of West indian cherry under salt stress and potassium fertilization. Revista Caatinga, Mossoró. v. 32, n. 2, p. 429-439, 2019. http://dx.doi.org/10.1590/1983-

21252019v32n216rc

FILGUEIRA, F. A. R. Novo manual de olericultura. 3. ed. Viçosa: Editora UFV, 2012. 421 p.

FREIRE, J. L. de O., CAVALCANTE, L. F., NASCIMENTO, R., REBEQUI, A. M. Teores de clorofila e composição mineral foliar do maracujazeiro irrigado com águas salinas e biofertilizante. Revista de Ciências Agrárias. v. 36, n. 1, p. 57-70, 2013.

MALAVOLTA, E.; VITTI, G. C.; OLIVEIRA, S. A. Avaliação do estado nutricional das plantas: princípios e aplicações. 2. ed. Piracicaba: Associação Brasileira de Potassa e do Fósforo, 1997. 319 p.

MUNNS, R.; TESTER M. Mechanisms of salinity tolerance. Annual Review of Plant Biology. Palo Alto, v. 59, p. 651-681, 2008.

OLIVEIRA, F. de A. de., CAMPOS, M. de S., OLIVEIRA, F. R. A., OLIVEIRA, M. K. T., MEDEIROS, J. F., MELO, T. K. Desenvolvimento e concentração de nitrogênio, fósforo e potássio no tecido foliar da berinjela em função da salinidade. Revista Brasileira de Ciências Agrárias. v. 6, n. 1, p. 37-45, 2011.

PRAZERES, S. da S., LACERDA, C. F. de., BARBOSA, F. E. L., AMORIM, A. V. ARAUJO, I. C. da S., CAVALCANTE, L. F. Crescimento e trocas gasosas de plantas de feijão-caupi sob irrigação salina e doses de potássio. Revista Agro@mbiente, v. 9, n. 2, p. 111-118, 2015.

PUÉRTOLAS, J.; LARSEN, E. K.; DAVIES, W.J.; DODD, I.C. Applying 'drought' to potted plants by maintaining suboptimal soil moisture improves plant water relations. Journal of Experimental Botany. v.68, n.9, 
p.2413-2424,

2017.

https://doi.org/10.1093/jxb/erx116.

RHOADES, J. P.; KANDIAH, A.; MASHALI, A. M. Uso de águas salinas para a produção agrícola. Estudos FAO 48, Campina Grande: UFPB, 2000. 117p.

RODRIGUES, V, DOS S., BEZERRA, F. M. L., SOUSA, G. G., FIUSA J. N., LEITE, K. N., VIANA, T. V DE. A. Produtividade da cultura do milho irrigado com águas salinas. Revista Brasileira de Engenharia Agrícola e Ambiental. v.24, n.2, p.101-105. 2020. https://doi.org/10.1590/1807-

1929/agriambi.v24n2p101-105

ROMHELD, V.; KIRKBY, E. A. Research on potassium in agriculture: needs and prospects. Plant and Soil, v.335, n.1, p.155-180, 2010. 10.1007/s11104-010-0520-1.

SILVA, F. A. S.; AZEVEDO, C. A. V. The Assistat Software Version 7.7 and its use in the analysis of experimental data. Africa Journal and Agriculture Researche, v. 11, n. 39, p.3733-3740, 2016.

SILVEIRA, JOAQUIM A G; SILVA, SÉRGIO L F; SILVA, EVANDRO N. Mecanismo biomoleculares envolvidos com a resistência ao estresse salino em plantas. In: GHEYI, Hans Raj; DIAS, Nildo da Silva; LACERDA, Claudivan Feitosa de. Manejo da Salinidade na Agricultura: Estudos Básicos e Aplicados. 2. ed. Fortaleza: Byte Systems Soluções Digitais, 2016. Cap. 13. p. 181-197.
SOUSA, G. G. DE; LACERDA, C. F. DE; CAVALCANTE, L. F.; GUIMARÃES, F. V. A.; BEZERRA, M. E. DE J.; SILVA, G. L. Nutrição mineral e extração de nutrientes de planta de milho irrigada com água salina. Revista Brasileira de Engenharia Agrícola e Ambiental, v.14, p.1143-1151, 2010.

SOUSA, G. G., MENDONÇA, A. de M., SALES, J. R. da S., JUNIOR, F. B. da S., MORAES, J. G. L., SOUSA, J. T. M. de. Morphophysiological characteristics of okra plants submitted to saline stress in soil with organic fertilizer. Comunicata Scientiae. v. 11, 3241, 2020. https://doi.org/10.14295/cs.v11i0.3241.

SOUSA, G. G., RODRIGUES, V. dos S., SOARES, S. da C., DAMASCENO, I. N., FUISA, J. N., SARAIVA, S. E. L. Irrigation with saline water in soybean (Glycine max (L.) Merr.) in a soil with bovine biofertilizer. Revista Brasileira de Engenharia Agrícola e Ambiental. v. 22, n. 9, p. 604-609, 2018. DOI: $\quad$ http://dx.doi.org/10.1590/18071929/agriambi.v22n9p604-609.

SOUZA, M. V. P., SOUSA, G. G., SALES, J. R. da S., FREIRE, M. H. da C., SILVA, G. L da., VIANA, T. V. de A. Saline water and biofertilizer from bovine and goat manure in the Lima bean crop. Revista Brasileira de Ciências Agrárias. v. 14, n. 3, p. 1-8, 2019.

TEIXEIRA P. C, DONAGEMMA G. K, FONTANA A. and TEIXEIRA W. G. 2017. Manual de Métodos de Análise de Solo, 3rd ed., Brasília: Embrapa, 573 p. 